\title{
Kısa Dalga Tedavisinin Idiyopatik Karpal Tünel Sendromundaki Etkinliği: Randomize Çift Kör Kontrollü Çalışma
}

\section{Effect of Short Wave Therapy in Idiopathic Carpal Tunnel Syndrome: A Randomized Double-Blind Controlled Study}

\author{
Zeynep Alev ÖZÇETE, Cihat ÖZTÜRK, Arzu YAĞIZ ON, Simin HEPGÜLER, Funda ATAMAZ ÇALIŞ \\ Ege Üniversitesi Tıp Fakültesi, Fiziksel Tıp ve Rehabilitasyon Anabilim Dalı, Izmir, Türkiye
}

\section{Özet}

Amaç: Ilımlı veya orta dereceli karpal tünel sendromunda (KTS) kesikli kısa dalga (KKD) ve kısa dalga (KD) tedavisinin birbirlerine ve plasebo tedaviye üstün olup olmadıklarının araştırılmasıdır.

Gereç ve Yöntem: Çalışma klinik ve elektrofizyolojik bulguları ılımlı-orta dereceli KTS ile uyumlu olan 60 el (45 hasta) üzerinde gerçekleştirildi. Olgular KD, KKD ve plasebo olmak üzere üç gruba randomize edildiler. Tüm gruplara 2 hafta süreyle, haftada 5 gün, günde 20 dakika olmak üzere 10 seans tedavi uygulandı. On iki hafta boyunca tüm gruplara tendon ve sinir kaydırma egzersizleri verildi. Tedavi öncesi, sonrası, 1. ve 3. ayda Boston Semptom Şiddet Skalası (BSŞS) ve Boston Fonksiyonel Kapasite Skalas (BFKS), el kavrama ve parmak sıkma gücü ve median sinir ileti çalıșmaları, uygulanan tedaviye kör olan bir araştırmacı tarafından gerçekleştirildi. Bulgular: Her üç grupta da, BSŞS ve BFKS skorlarında tedavi öncesi değerlere göre istatistiksel anlamlı düzelme olurken $(p<0,05)$, düzelme oranları açıından gruplar arasında fark saptanmadı $(p>0,05)$. El kavrama gücünde sadece KD grubunda, 1.ve 3.ayda istatistiksel anlamlı artış saptandı $(p<0,05)$. Parmak sıkma gücünde KD grubunda tedavi sonrası, 1.ay ve 3.ayda istatistiksel anlamlı iyileşmeler saptandı $(p<0,05)$. Median sinir duyusal ileti hızlarında sadece KD grubunda istatistiksel anlamlı iyileşme saptanırken $(p<0,05)$, median sinir motor distal latans değerlerinde her üç grupta da istatistiksel anlamlı değişim saptanmadı $(p>0,05)$.

Sonuç: Bu çalışmada, karpal tünel sendromunda KD tedavisinin subjektif klinik parametreler üzerinde etkin olduğu, ancak bu etkinliğin plaseboya üstün olmadığı, objektif klinik parametreler olan el kavrama ve parmak sıkma gücünde KKD tedavisine ve plaseboya göre daha üstün olduğu, median sinir duyusal ileti hızlarında düzelmeye yol açtığı sonucuna ulaşılmıştır. Türk Fiz Tıp Rehab Derg 2013;59:103-7.

Anahtar Kelimeler: Karpal tünel sendromu, konservatif tedavi, kısa dalga tedavisi, kesikli kısa dalga tedavisi, sinir ve tendon kaydırma egzersizleri

\section{Summary}

Objective: The aim of this study was to investigate superiority of short wave (SW) and pulsed short wave (PSW) therapies to each other and to placebo in mild and moderate carpal tunnel syndrome (CTS).

Materials and Methods: Sixty hands (45 patients) with mild-to-moderate CTS were randomly assigned to receive SW, PSW or sham therapy. All the treatments were applied 20 minutes once a day, 5 days a week, for 2 weeks. Nerve and tendon gliding exercises were given to all hands for 12 weeks. The patients were evaluated before and after the treatment and at the $1^{\text {st }}$ and the $3^{\text {rd }}$ months using the Boston Symptom Severity Scale (BSSS), Boston Functional Status Scale (BFSS), grip strength, pinch strength and median nerve conduction studies by a physician who had been blinded to the treatment.

Results: Although statistically significant improvements were obtained in BSSS and BFSS scores in all groups $(p<0.05)$, the differences between the groups were not significant $(p>0.05)$. Grip strength increased significantly only in SW group at the 1 st and the 3rd months $(p<0.05)$ Pinch strength increased significantly after the treatment and at the $1^{\text {st }}$ and $3^{\text {rd }}$ months in SW group $(\mathrm{p}<0.05)$. Median nerve sensory conduction velocities increased significantly only in SW group $(p<0.05)$.

Conclusion: Although SW therapy is effective on subjective clinical parameters, this efficacy is not superior to placebo. SW therapy is effective on objective clinical parameters compared to PSW therapy and placebo and it increases median nerve sensory conduction velocities in mild and moderate CTS. Turk / Phys Med Rehab 2013;59:103-7.

Key Words: Carpal tunnel syndrome, conservative treatment, nerve and tendon gliding exercises, short wave treatment, pulsed short wave treatment

Yazışma Adresi/ Address for Correspondence: Dr. Cihat Öztürk,Ege Üniversitesi Tıp Fakültesi, Fiziksel Tıp ve Rehabilitasyon Anabilim Dalı, Izmir, Türkiye Tel.: +902323903689 E-posta: cihat.ozturk@ege.edu.tr

Geliş Tarihi/Received: Ocak/January 2012 Kabul Tarihi/Accepted: Şubat/February 2012

(๑) Türkiye Fiziksel Tıp ve Rehabilitasyon Dergisi, Galenos Yayınevi tarafından basılmıștı./ @ Turkish Journal of Physical Medicine and Rehabilitation, Published by Galenos Publishing. 


\section{Giriş}

Karpal tünel sendromu (KTS) median sinirin el bileğinde karpal tünel içindeki kompresyonu sonucu ortaya çıkan bir klinik tablo olup, en sık görülen, en iyi tanımlanmış ve incelenmiş tuzak nöropatisidir. Sendromun özgün bulguları median sinir trasesinde el bileğinden parmaklara yayılan uyuşma, karıncalanma ve ağrı yakınmalarıdır. Noktürnal ağrı ve paresteziler başlangıçta tek belirti olarak karşımıza çıkabilir. İleri dönemlerde tenar kaslarda güçsüzlük ve atrofi, az sayıda olguda Raynaud Fenomeni ve otonomik sinir tutulumuna bağlı ait vazomotor belirtiler ve büllöz ülserasyonlar görülebilir $(1,2)$. KTS'de tanı öykü, klinik ve fizik muayene bulguları ile bu bulguların, elektronörofizyolojik olarak desteklenmesine dayanır. Konservatif tedavide uygulanan yöntemler çeşitlidir ve birbirlerine üstünlükleri tartışmalıdır (2-4). Günümüzde önerilen ve yaygın kullanılan konservatif yöntemler splintleme, iş ve aktivite modifikasyonu, lokal kortikosteroid enjensiyonları, nonsteroidal antiinflamatuvarlar, ultrason, lazer, yoga, tendon ve sinir kaydırma egzersizleridir $(5,6)$. Bu yöntemlerde, sendromun patofizyolojisinde rol oynadığı kabul edilen mikrovasküler yetmezlik, mekanik kompresyon ve vibrasyon mekanizmalarının neden olduğu sinovyal inflamasyonun ve tünel çevresi ödemin giderilmesi, böylece sinir üzerindeki kompresyonun azaltılması amaçlanmaktadır $(5,7)$. Mikrovasküler dolaşım bozukluğunun düzeltilmesi, böylece iskemiye bağlı olarak meydana gelen epinöral ve endonöral ödemin azaltılması konservatifyöntemlerde diğer bir amaçtır (5). Beslenme bozukluğunun düzeltilmesi; sinir liflerinin ileri dejenerasyonu ve sonrasında ortaya çıkabilecek fonksiyon bozukluğunu önler ve Sinir liflerindeki iskemiye bağlı ağrı ve parestezi gibi semptomlarda azalma sağlar (8).

Birçok klinik durumda kullanılan kısa dalga (KD) tedavisinin dolaşımı arttırdığı, periferik sinir ileti hızında artışlara neden olduğu, bağ dokusu esnekliğini arttırdığı, analjezik etki sağladığı ve ısı etkisiyle metabolizmayı artırıp enzim aktivitesini yükselttiği bilinmektedir (9). Tüm bu etkilerin sadece ısı etkisiyle açıklanamayacağı, bazı terapötik etkilerinin elektrik ve manyetik alanın birbirleri ile ve biyolojik dokularla etkileşimine bağlı olduğu düşünülmektedir $(10,11)$. Bu nedenle, dokularda Isıtıcı etkisi olmayan ya da çok az olan kesikli kısa dalga (KKD) uygulaması gündeme gelmiştir (11-13). KKD uygulamasının periferik kan dolaşımını arttırdığı (14), hücre membranlarında iyon dağılımını düzenleyerek ve membran permeabilitesini arttırarak antiinflamatuvar, ödem çözücü $(11,15)$ ve analjezik etkili olduğu $(16,17)$ gösterilmiştir. Özellikle analjezik ve ödem çözücü etkileri nedeniyle yumuşak doku lezyonlarında geniş kullanım alanı bulmuştur $(13,18,19)$. KKD tedavisinin ayrıca, periferik sinir sistemi rejenerasyonunu hızlandırdığı çeşitli çalışmalarda gösterilmiştir (11-13).

Literatürde KTS'nin konservatif tedavisinde, KD ve KKD tedavisinin her ikisinin kullanıldığı ve karşılaştırıldığı bir çalışma mevcut değildir. KTS'nin patofizyolojisinde öne sürülen teoriler ile KD tedavisinin etki mekanizmaları arasındaki örtüşmeler, bize bu tedavi yönteminin KTS'nin klinik ve elektrofizyolojik parametreleri üzerinde düzelme sağlayabileceğini düşündürmüştür. KKD tedavisinin periferik sinir rejenerasyonunu hızlandırıcı etkisi (11-13) ise, KKD tedavisinin KD tedavisine göre daha üstün olabileceği kanaatini uyandırmıştır. Bu randomize kontrollü çalışmanın amacı, ılımlı veya orta dereceli idiyopatik karpal tünel sendromunda KKD ve KD tedavisinin birbirlerine ve plasebo tedaviye üstün olup olmadıklarının araştırılmasıdır.

\section{Gereç ve Yöntem}

Hasta seçimi: Çalışma öncesi Ege Üniversitesi Tıp Fakültesi Etik kurulu tarafından onay alındı (Etik Kurul Onay Tarih/No: 05.01.2010 / 09-10.1/10). Çalışmaya dahil edilecek hastalar, Mart 2010 ile Mart 2011 tarihleri arasında elde uyuşma ve ağrı şikayeti ile polikliniğimize başvuran hastalar arasından seçildi. Diabetes Mellitus, akut travma, romatolojik hastalık, gebelik, hipotiroidi, hipertiroidi gibi KTS için predispoze hastalığı olanlar, tenar bölgede atrofi veya tenar kaslarda güçsüzlüğü olanlar, önceki bir ay içinde oral steroid gibi medikal tedavi almış veya fizik tedavi programına girmiş olanlar, önceki üç ay içinde el bileğine steroid enjeksiyonu yapılmış olanlar, KD tedavisinin kontrendike olduğu hastalar (kalp pili, metal implant, gebelik gibi) çalışma dışı bırakıldı. Elde median sinir dağılımına uyan bölgede parestezi, ağrı ve/veya vazomotor semptomları olan, fizik muayenede Tinel, Phalen ve karpal kompresyon testlerinin en az biri pozitif bulunan hastalarda, kliniğimizde bulunan EMG cihazıyla (DantecTM Keypoint ${ }^{\circledR}$ Net), yüzeyel kayıt ve uyarı elektrodları kullanılarak standart yöntemlerle sinir iletim çalışmaları gerçekleştirildi. Median sinir duysal duyusal iletimleri 1. parmaktan antidromik yöntemle kaydedildi. Uyarıcı - kayıtlayıcı elektrod arası mesafe $10 \mathrm{~cm}$ olacak şekilde standardize edildi. Median sinir motor iletimlerinde el bileği düzeyinde median sinirin supramaksimal uyarımı ile abdüktör pollicis brevis kasından birleşik kas aksiyon potansiyeli elde edildi. Uyarıcı- kayıtlayıcı elektrod arası mesafe $6 \mathrm{~cm}$ olacak şekilde standardize edildi. Amerikan elektrodiagnostik tıp tanı kritelerlerine ve laboratuarımızda kullanılan referans değerlere göre ılımlı ve orta dereceli KTS tanısı alan olgular çalışmaya dahil edildi (20). Bu kriterlere göre, median sinir motor distal latansı (MDL) normal iken duysal ileti hızı (DiH) yavaşlamış (<42 $\mathrm{m} / \mathrm{sn}$ ) olanlar ılımlı, DïH yavaşlamış ve MDL uzamış (>4,2 msn) olanlar ise orta dereceli KTS olarak kabul edildi. Bu incelemeler sonucunda servikal radikülopati ya da polinöropati saptanan olgular, MDL 6 msn'den uzun olan, median sinir birleşik kas aksiyon potansiyeli elde edilemeyen veya tenar atrofisi olan olgular çalışma dışı bırakıldı.

\section{Çalışma Tasarımı}

Çalışma klinik ve elektrofizyolojik bulguları ılımlı-orta dereceli KTS ile uyumlu olan 60 el (45 hasta) üzerinde gerçekleştirildi. Olgular üç gruba randomize edildiler. Randomizasyon, klinik ve elektrofizyolojik bulgulara kör olan farklı bir araştırmacı tarafından, randomizasyon şeması kullanılarak, hastaların geliş sırasına göre basit randomizasyon yöntemiyle yapıldı. Bilateral KTS'si olan hastaların her iki eli aynı gruba alındı, ancak değerlendirmeler her iki el için ayrı ayrı yapıldı. Grup 1'deki hastalara (15 hasta, 20 el) KD, grup 2'deki hastalara (15 hasta, 20 el) KKD, grup 3'deki hastalara sham (15 hasta, 20 el) tedavileri uygulandı. Hastalara 2 hafta süreyle, haftada 5 gün, günde 20 dakika olmak üzere 10 seans tedavi verildi. Tedaviler, aynı terapist tarafından, Enraf-Nonius Delf Curapulse ${ }^{\circledR} 419$ kısa dalga cihazı ile uygulandı. Uygulama $8 \mathrm{~cm}$ çapında kapasitör elektrotlarla, kondansatör alan metoduyla yapıldı. Elektrodlar dirsek $90^{\circ}$ de, el bileği nötral pozisyonda iken, karpal tünel bölgesine bakacak şekilde el bileğine paralel olarak yerleştirildi (el bileğinin volar yüzüne 1-2 cm, dorsal yüzüne 2-3 cm mesafede). Sürekli uygulamalarda intensite 4 (160 Watt), kesikli uygulamalarda pulse süresi $400 \mu$ sn, pulse frekansı 82 $\mathrm{Hz}$, intensite 6 (19,68 Watt) olarak uygulandı. Üç gruba da tedavi boyunca aynı fizyoterapist tarafından önce tendon kaydırma egzersizleri $(7,21)$ ardından sinir kaydırma egzersizleri 
$(7,21)$ uygulandı ve tedavi sonrasında aynı egzersizleri ev egzersiz programı şeklinde uygulamaları önerildi. Bu amaçla olgulara görsel materyal verildi. Bu egzersizler sırasında omuz ve dirsek $90^{\circ}$ fleksiyonda ve pronasyonda olacak şekilde, her pozisyon 5 saniye süreli, her egzersiz 10 tekrar şeklinde ve günde 5 defa uygulanması önerildi. Klinik ve elektrofizyolojik değerlendirmeler, uygulanan tedaviye kör olan bir araştırmacı tarafından gerçekleştirildi.

Tedavi Öncesi Değerlendirme

Tüm hastalar ayrıntılı olarak sorgulanarak ve muayene edilerek semptom ve fizik muayene bulguları kaydedildi ve "Boston Karpal Tünel Sendromu Sorgulama Anketi" uygulandı. Levine ve ark. (22) tarafından 1993 yılında geliştirilen bu anketin Türk toplumu geçerlilik ve güvenirlilik çalışması Sezgin ve ark. (23) tarafından yapılmıştır. Boston Semptom Şiddet Skalası (BSŞS) ve Boston Fonksiyonel Kapasite Skalası (BFKS) olmak üzere iki bölümden oluşmaktadır. BSŞS semptomlara yönelik 11 sorudan oluşur. Her soruda 1 ile 5 arasında puan alan beş ayrı cevap bulunmaktadır. Ortalama skor, toplam puan soru sayısına bölünerek elde edilir. Yüksek puan şiddetli semptomu göstermektedir. BFKS ise fonksiyonel kapasiteye yönelik 8 sorudan oluşur. Yine her soruda 1 ile 5 arasında puan alan beş ayrı cevap bulunmaktadır. Ortalama skor, toplam puan soru sayısına bölünerek elde edilir. Yüksek puan fonksiyonel kapasitenin azaldığını gösterir (22).

Tüm hastaların el kavrama güçleri Jamar ${ }^{\circledR}$ el dinamometresi ile, parmak sıkma güçleri ise Jamar ${ }^{\circledR}$ pinçmetre ile ölçüldü. Ölçümler hasta oturur pozisyonda, omuz addüksiyonda ve nötral rotasyonda, dirsek $90^{\circ}$ fleksiyonda, ön kol nötral pozisyonda yapıldı. Ölçümler 3 kez yapılarak ortalamaları alındı. Her ölçüm arasında 30 sn dinlenme arası verildi.

Çalışmaya dahil edilen ellerde elde edilen median sinir DïH ve MDL değerleri kaydedildi.

\section{Kontrol Değerlendirmeleri}

Tedaviyi yarım bırakan hasta olmadı ve tüm hastalar önceden belirtilen tarihlerde kontrollerine geldi. Klinik değerlendirmeler 2 haftalık tedavi programı sonrasında, tedavi sonrası 1. ve 3. ayda kaydedildi. Elektrofizyolojik incelemeler 3. ayda tekrarlanarak median sinir DïH ve DML kayıt edildi.

\section{İstatistiksel Analiz}

Çalışmada elde edilen bulgular, Ege Üniversitesi Biyoistatistik ve Ţıbbi Bilişim Anabilim Dalı'nda "SPSS 19,0 for Windows" programı kullanılarak analiz edildi. Her bir grupta ve ölçüm zamanında (tekrarlı ise) nümerik değişkenlerin normal dağılışa uyumları Shapiro-Wilk Testi ile incelendi. Zaman içinde tekrarlı ölçülen değişkenlerin, gruplar arası, ölçüm zamanları arası ve grup*zaman etkileşimi Tekrarlayan Ölçümler için Varyans Analizi ile incelendi. Etkileşimin önemli çıtığı değişkenlerin gruplar arası karşılaştırılmasında, tedavi öncesi değerleri için Tek Yönlü Varyans Analizi kullanılırken, tedavi sonrası değerleri için Kovaryans Analizi (tedavi öncesine göre düzeltme yapıldı) kullanıldı. Ayrıca, her grup kendi içinde zamana göre değişim yönünden yine Tekrarlayan Ölçümler için Varyans Analizi ile incelendi. Tüm varyans analizlerinde farkların anlamlı çıktığı durumlarda ikili analizler Bonferroni Test yöntemi kullanılarak gerçekleştirildi ( $p<0,0167$ ise farklılık anlamlı kabul edildi.). Semptom ve fizik muayene bulguları gibi niteliksel verilerin (kategorik değişkenlerin) karşılaştırılmasında Ki-Kare Testi uygulandı. Çalışma boyunca bir kez ölçülen nümerik veriler gruplar arasında Tek Yönlü Varyans Analizi kullanılarak karşılaştırıldı. Nümerik değiş̧kenler ortalamaıstandart sapma olarak özetlendi ve tüm istatistiksel hipotez kontrolleri $\alpha=0,05$ önem seviyesinde (yani $\mathrm{p}<0,05$ olan değerler istatistiksel olarak anlamlı kabul edildi) gerçekleştirildi.

\section{Bulgular}

Çalışmaya alınan hastaların demografik bilgileri Tablo 1'de verilmektedir. Çalışmaya alınan 45 hastanın 41'i kadın, 4'ü

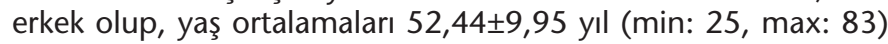
idi. KKD grubunun yaş ortalaması KD grubuna göre anlamlı yüksekti $(p<0,05)$. Kadın-erkek dağılımı açısından üç grup arasında anlamlı fark yoktu $(p>0,05)$. Hastaların vücut kitle indeksi $(30,27 \pm 5,72)$ ve semptomların süresi $(18,85 \pm 14,11$ ay) açısından gruplar arasında anlamlı fark saptanmadı ( $>0,05)$.

Her üç grupta tedavi öncesi elde edilen klinik ve elektrofizyolojik parametre değerleri karşılaştırıldığında, KKD grubundaki ellerin BSŞS ve BFKS skorlarının diğer gruplara göre anlamlı yüksek olduğu görüldü $(p<0,05)$ (Tablo 2). El kavrama ve parmak sıkma güçleri ve sinir ileti değerleri açısından başlangıçta gruplar arasında anlamlı fark yoktu $(p>0,05)$ (Tablo 2 ve 3$)$.

Her üç grupta da, tedavi sonrası (TS), 1. ay ve 3. ay kontrollerde elde edilen BSŞS ve BFKS skorlarında tedavi öncesi değerlere göre istatistiksel anlamlı düzelme olduğu görüldü $(p<0,05)$. Tedavi öncesi BSŞS ve BFKS skorlarlarında düzeltme yapılarak kovaryans analizi ile gruplar arası karşılaştırma yapıldığında, TS, 1.ay ve 3.aydaki düzelmelerin gruplar arasında istatistiksel anlamlı farklılık göstermediği saptandı ( $p>0,05)$, El kavrama gücünde TS, 1.ay ve 3.ayda tüm gruplarda artışlar görülürken, sadece KD grubundaki 1 . ay ve 3 . aydaki artışlar istatistiksel olarak anlamlıydı $(p<0,05)$ (Tablo 2$)$. 1.ay ve 3 . aydaki artışlar gruplar arasında karşılaştırıldığında 1.ayda sadece KKD grubuna göre, 3.ayda ise hem KKD hem de plasebo grubuna göre KD grubunda istatistiksel olarak anlamlı bir iyileşme olduğu görüldü $(p<0,05)$. Parmak sıkma gücünde ise, KD grubunda TS, 1. ay ve 3.ayda, istatistiksel anlamlı iyileşmeler saptanırken $(p<0,05)$, plasebo grubundaki değişimler istatistiksel anlamlı düzeyde değildi ( $p>0,05)$. KKD grubunda da 3.ayda istatistiksel anlamlı iyileşme görülmekle birlikte, tedavi öncesi değerlerde düzeltme

Tablo 1. Çalışma gruplarının demografik bilgileri.

\begin{tabular}{|c|c|c|c|c|}
\hline & KD & KKD & Plasebo & Tüm olgular \\
\hline El sayısı $(n)$ & 20 & 20 & 20 & 60 \\
\hline Yaş (yıl) (ort $\pm S S)$ & $47,53 \pm 9,50$ & $57,20 \pm 9,63^{*}$ & $52,60 \pm 8,83$ & $52,44 \pm 9,95$ \\
\hline VKi $\left(\mathbf{k g} / \mathrm{m}^{2}\right)$ (ort $\left.\pm S S\right)$ & $29,44 \pm 4,85$ & $29,19 \pm 6,60$ & $32,19 \pm 5,48$ & $30,27 \pm 5,72$ \\
\hline Semptom süresi (ay) (ort \pm SS) & $19,85 \pm 12,09$ & $19,95 \pm 10,12$ & $19,75 \pm 19,22$ & $18,85 \pm 14,11$ \\
\hline
\end{tabular}

*KD grubuna göre istatistiksel anlamlı farklııı (Tek yönlü varyans analizi, $p<0,05$ ) 
yapılarak kovaryans analizi ile gruplar arası karşılaştırma yapıldığında, 3.ayda KD grubundaki iyileşmenin KKD grubuna göre daha anlamlı olduğu $(p<0,05)$, KKD grubundaki iyileşmenin plasebodan farklı olmadığı görüldü ( $p>0,05)$.

3. ayda yapılan sinir iletim çalışmalarının tedavi öncesi değerlere göre karşılaştırılmasında, duyusal ileti hızlarında sadece KD grubunda istatistiksel anlamlı iyileşme saptandı $(p<0,05)$. Median sinir MDL değerlerinde ise her 3 grupta da istatistiksel anlamlı değişim saptanmadı $(p>0,05)$ (Tablo 3$)$.

\section{Tartışma}

Bu randomize, kontrollü çift kör çalışmada, ılımlı veya orta dereceli idiyopatik KTS'de KKD ve KD tedavisinin her ikisinin de subjektif klinik parametreler üzerinde etkin olduğu, ancak bu etkinliğin plaseboya üstün olmadığı görülmüştür. Objektif

Tablo 2. Çalışma gruplarında Boston Anket değerlerinin, el kavrama gücü ve parmak sıkma gücünün gruplar arası ve grup içi karşılaştırılması.

\begin{tabular}{|c|c|c|c|c|}
\hline & & $\begin{array}{l}\text { KD } \\
\text { (ort } \pm S S)\end{array}$ & $\begin{array}{l}\text { KKD } \\
\text { (ort } \pm S S)\end{array}$ & $\begin{array}{l}\text { Plasebo } \\
\text { (ort } \pm \text { SS) }\end{array}$ \\
\hline BSŞS & $\begin{array}{l}\text { TÖ } \\
\text { TS } \\
\text { 1.ay } \\
\text { 3.ay }\end{array}$ & $\begin{array}{l}26,5 \pm 7,8 \\
19,2 \pm 5,5^{a} \\
19,8 \pm 7,2^{a} \\
19,0 \pm 7,2^{a}\end{array}$ & $\begin{array}{l}31,2 \pm 10,7^{*} \\
21,5 \pm 6,1^{a} \\
21,7 \pm 7,4^{a} \\
20,6 \pm 6,8^{a}\end{array}$ & $\begin{array}{l}21,9 \pm 7,6 \\
17,9 \pm 6,7 a \\
17,2 \pm 4,2^{a} \\
16,5 \pm 3,7 a\end{array}$ \\
\hline BFKS & $\begin{array}{l}\text { TÖ } \\
\text { TS } \\
\text { 1. ay } \\
\text { 3. ay }\end{array}$ & $\begin{array}{l}16,9 \pm 5,3 \\
13,2 \pm 4,1^{a} \\
13,5 \pm 4,4^{a} \\
13,2 \pm 4,3^{a}\end{array}$ & $\begin{array}{l}21,9 \pm 8,1^{*} \\
16,9 \pm 5,7^{a} \\
17,5 \pm 6,4^{a} \\
15,1 \pm 5,5^{a}\end{array}$ & $\begin{array}{l}16,0 \pm 5,7 \\
13,4 \pm 4,9 a \\
13,2 \pm 4,8 a \\
13,5 \pm 5,3^{a}\end{array}$ \\
\hline $\begin{array}{l}\text { El kavrama } \\
\text { gücü }(\mathrm{kg})\end{array}$ & $\begin{array}{l}\text { TÖ } \\
\text { TS } \\
\text { 1. ay } \\
\text { 3. ay }\end{array}$ & $\begin{array}{l}20,8 \pm 6,2 \\
22,9 \pm 6,05 \\
23,6 \pm 6,6^{a} \\
24,1 \pm 5,2^{a}\end{array}$ & $\begin{array}{l}18,1 \pm 8,4 \\
19,0 \pm 8,1 \\
18,9 \pm 8,32 \\
19,2 \pm 7,8\end{array}$ & $\begin{array}{l}21,5 \pm 6,7 \\
22,5 \pm 5,8 \\
22,7 \pm 4,9 \\
22,5 \pm 5,4\end{array}$ \\
\hline $\begin{array}{l}\text { Parmak } \\
\text { sıkma gücü (kg) }\end{array}$ & $\begin{array}{l}\text { TÖ } \\
\text { TS } \\
\text { 1. ay } \\
\text { 3. ay }\end{array}$ & $\begin{array}{l}5,1 \pm 1,7 \\
6,1 \pm 1,6^{a} \\
5,9 \pm 1,4^{a} \\
6,2 \pm 1,6^{a}, b\end{array}$ & $\begin{array}{l}4,6 \pm 1,7 \\
4,8 \pm 1,7 \\
4,9 \pm 2,1 \\
5,1 \pm 2,0^{a}\end{array}$ & $\begin{array}{l}5,8 \pm 2,1 \\
5,8 \pm 1,7 \\
5,9 \pm 2,1 \\
6,1 \pm 1,7\end{array}$ \\
\hline
\end{tabular}

BSSS: Boston Semptom Siddet Skalası skoru, BFKS: Boston Fonksiyonel Kapasite Skalası skoru, TÖ: Tedavi Öncesi, TS: Tedavi Sonrası, *:Tedavi öncesi değerlerin gruplar arası karşılaştırmasında istatistiksel anlamlı farklılık (tek yönlü varyans analizi ve Bonferroni testi, $\mathrm{p}<0,05$ ), a: Tedavi sonrası, 1 .ay ve 3 .ay değerlerinde tedavi öncesi değerlere göre istatistiksel anlamlı farklılık (tekrarlayan ölçümler için varyans analizi ve Bonferroni testi, $p<0,05),{ }^{b}:$ KKD grubuna göre anlamlı farklılık (kovaryans analizi, $\mathrm{p}<0,05$ ).

Tablo 3. Çalışma gruplarında median sinir ileti hızı değerlerinin gruplar arası ve grup içi karşılaştırılması.

\begin{tabular}{lllll} 
& & KD & KKD & Plasebo \\
\hline $\begin{array}{l}\text { Duysal ileti } \\
\text { hizı (m/sn) } \\
\text { (ort } \pm \text { SS) }\end{array}$ & TÖ & $35,1 \pm 4,3$ & $36,5 \pm 3,1$ & $34,6 \pm 4,2$ \\
& 3. ay & $37,3 \pm 5,1^{1 \underline{a}}$ & $37,4 \pm 4,2$ & $34,7 \pm 4,1$ \\
$\begin{array}{l}\text { Motor distal } \\
\text { latans (msn) } \\
\text { (ort } \pm \text { SS) }\end{array}$ & TÖ & $4,4 \pm 0,7$ & $4,1 \pm 0,7$ & $4,4 \pm 0,7$ \\
& 3. ay & $4,2 \pm 0,7$ & $4,1 \pm 0,7$ & $4,3 \pm 0,7$ \\
\hline
\end{tabular}

ạ: Tedavi öncesi değerlere göre istatistiksel anlamlı farklılık (Tek yönlü varyans analizi, $p<0,05$ ) klinik parametreler olan el kavrama ve parmak sıkma gücünde KD tedavisinin KKD tedavisine ve plaseboya göre daha üstün olduğu saptanmıştır. KD grubunda median sinir duysal ileti hızlarında da istatistiksel anlamlı düzelmeler kaydedilmiştir.

Çalışmamıza ılımlı veya orta dereceli idiopatik KTS tanılı olgular dahil edilmiştir. Ilımlı ve orta dereceli olguların seçilmesinin nedeni, ileri olguların tedavisinde cerrahi yöntemlerin öncelikli düşünülmesi gerekliliğidir (24). İdiyopatik olguların seçilmesindeki amaç ise, KTS'ye neden olan klinik durumdaki düzelme veya kötüleşmelerin sonuçlarımızı etkileyebilecek olmasıdır.

Çalışmamızda subjektif klinik yakınmaların değerlendirilmesinde Boston anketi kullanılmıştır. Bu ankette ağrının yanı sıra nokturnal semptomlar, uyuşukluk ve fonksiyonellik de değerlendirilmektedir. Tedavi sonrasında, Boston semptom şiddet ve fonksiyonel kapasite skorlarında her üç grupta da tedavi öncesi değerlere göre anlamlı düzelmeler saptanmış, ancak gruplar arasında istatistiksel anlamlı farklılık saptanmamıştır. KD ve KKD tedavisi subjektif klinik parametreler üzerinde etkili olmakla birlikte, bu etkinin plasebodan farklı olmaması, bu etkinin öncelikle plasebo grubuna da vermiş olduğumuz tendon ve sinir kaydırma egzersizlerine bağlı olabileceğini düşündürmüştür (21). Ayrıca, plasebo grubundaki hastaların tedavi etkinliği beklentileri nedeniyle endojen opioidlerin salınışındaki artışa bağlı olarak plasebo analjezinin ortaya çıkabileceği de bilinmektedir (25).

Çalışmamızda objektif klinik kriter olarak el kavrama gücü ve parmak sıkma gücü değerlendirilmiştir. El kavrama gücünde tedavi sonrası ve kontrollerde tüm gruplarda artış olmakla birlikte, bu artışın tedavi sonrası kontrollerinde KKD ve plaseboya göre sadece KD grubunda istatistiksel olarak anlamlı olduğu saptanmıştır. Parmak sıkma gücünde ise, tüm gruplarda tedaviden sonra artışlar görülmekle birlikte, KKD grubunda sadece 3. ayda anlamlıyken, KD grubunda tedavi sonrası tüm kontrollerde artışlar anlamlıydı. KKD grubundaki artışın 3. ayda plasebodan farklı olmadığı halde KD grubundaki iyileşmenin diğer gruplara göre daha anlamlı olduğu saptanmıştır. KD grubundaki artışın KKD grubuna göre anlamlı oranda daha fazla olması, bize bu etkinin KD tedavisinin yumuşak dokulardaki derin Isıtıcı etkilerine bağlı olabileceğini düşündürmüştür. Nitekim, yine bir derin ısıtıcı olan ultrason tedavisi ile yapılmış çalışmalarda, KTS semptom şiddeti ve fonksiyonel skorlarında, ağrı skorlarında ve el kavrama ve parmak sıkma gücünde plaseboya oranla anlamlı düzelmeler saptanmıştır $(26,27)$. Araştırmacılar bu etkiyi US'nin derin ısıtıcı etkilerinden dolayı dokularda meydana gelen kan akımında artış, lokal metabolizmada artış ve bunların sonucu olan doku rejenerasyonunda artışa bağlamışlar, aynı zamanda ağrı ve inflamasyonu azaltıcı etkilerin sinir rejenerasyonunu kolaylaştıracağının altını çizmişlerdir $(26,27)$.

Çalışmamızda KD tedavisiyle median sinir duysal duyusal ileti hızlarında istatistiksel anlamlı artışlar saptanmıştır. KD tedavisinin sinir iletim hızı üzerine etkilerinin incelendiği çalışmalara literatürde rastlanamamış olmakla beraber benzer bir derin ısıtıcı olan ultrason (US) ile yapılmış çok sayıda çalışma mevcuttur $(26,28-30)$. Bu çalışmalarda US'nin sürekli dozda uygulanması ile periferik sinirlerde termal etkisine bağlı olarak ileti hızının arttırdığı bildirilmiştir $(29,30)$. KD grubundaki duyusal ileti hızındaki bu istatistiksel artış, KD'nin periferik sinirler üzerine olan termal etkileri sonucu sinir ileti hızında artış meydana getirmiş olabileceği ile açıklanabilir. Ancak sinir iletim hızlarındaki artış klinik olarak anlamlı görünmemektedir. KTS'de hastaların ağrı semptomları ve ağrıya 
bağlı fonksiyon kayıplarının nedeni daha çok küçük çaplı miyelinli veya miyelinsiz sinir lifleri ile ilişkilidir ve normal elektrofizyolojik çalışmalarda bu sinir liflerini değerlendirmek mümkün olmayabilir (31). Çalışmamızda semptom şiddet ve fonksiyonel kapasite skorları ve ağrı skorlarında KD tedavileri ile düzelme sağlanırken elektrofizyolojik parametrelerde klinik olarak anlamlı düzelme sağlanamamasının nedeni bu olabilir.

Çalışmamızda KKD uygulamasıyla sinir iletim hızlarında istatistiksel anlamlı düzelme gözlenmemiştir. Yağız ve ark. (8)'nın KKD tedavisinin kontrol grubu ile karşılaştırdıkları çalışmalarında, KKD tedavisi alan grupta elektrofizyolojik parametrelerde istatistiksel anlamlı düzelmeler saptanmıştır. Bizim çalışmamıza benzer şekilde aynı pulse frekansı ve intensite kullanılmış olmakla beraber çalışmamızdan farklı olarak seans süresi $30 \mathrm{dk}$ ve tedavi süresi 20 gün olarak uygulanmıştır. Tedavi ve seans süresinin bizim çalışmamızdan daha uzun olması tedavi etkinliğini artıran bir faktör olabilir.

Çalışmamızın en güçlü yanı, randomize, çift kör ve plasebo kontrollü bir çalışma olmasıdır. Çalışmamızın en önemli kısıtlılıkları ise az sayıda hasta üzerinde yapılmış olması, takip süresinin 3 ay olması ve randomizasyona bağlı olarak her gruptaki başlangıç değerlerinin farklı olmasıdır. Semptom şiddet ve fonksiyonel skorlarda azalma, el kavrama ve parmak sıkma gücünde artışlar elde etmiş olmamıza karşın elektrofizyolojik parametrelerde klinik düzelme elde edememiş olmamız olgulara uygulanan tedavide "tedavi ve seans süresi kısa mı?" sorusunu akla getirmiştir. Bu durum da çalışmamızdaki diğer bir kısıtlılık olarak düşünülebilir. Her gruba tendon kaydırma egzersizlerinin verilmiş olması da, elde edilen tedavi etkilerinin tek başına KD ve KKD ile açıklanmasını güçleştiren bir başka kısıtlılıktır. Bu kısıtıılıklara rağmen, KD tedavisinin KKD tedavisinden daha üstün olduğu sonucuna ulaşılmıştır. Daha fazla hastada, daha uzun süreli sonuçların değerlendirildiği plasebo kontrollü çalışmalara gereksinim bulunmaktadır.

\section{Çıkar Çatışması}

Yazarlar herhangi bir çıkar çatışması bildirmemişlerdir.

\section{Kaynaklar}

1. Bengston KA, Brault JS. Hand Disorders. In: Delisa J A, editor. Physical Medicine \& Rehabilitation Principles and Practice. 3th ed. USA: Lippincott Williams \& Wilkins; 2005. p. 843-54.

2. Ertekin C. Santral ve Periferik EMG Anatomi-Fizyoloji-Klinik. Izmir: Meta Basım Matbaacilık; 2006.

3. Piazzini DB, Aprile I, Ferrara PE, Bertolini C, Tonali P, Maggi L, et al. A systematic review of conservative treatment of carpal tunnel syndrome. Clin Rehabil 2007;21:299-314.

4. O'Connor D, Marshall S, Massy-Westropp N. Nonsurgical treatment (other than steroid injection) for carpal tunnel syndrome. Cochrane Database Syst Rev 2003;(1):CD00321.

5. Hayes EP, Carney K, Wolf J. Carpal tunnel syndrome. In: Mackin EJ, Callahan AD, Skirven TM, Schneider LH, Osterman AL, editors. Rehabilitation of the Hand and Upper Extremity. St Louis, Mosby; 2002. p. 643-57.

6. Goodyear-Smith F, Arroll B. What can family physicians offer patients with carpal tunnel syndrome other than surgery? A systemic review of nonsurgical management. Ann Fam Med 2004; 2:267-73.

7. Rozmaryn LM, Dovelle S, Rothman ER, Gorman K, Olvey KM, Bartko JJ. Nerve and tendon gliding exercises and the conservative management of carpal tunnel syndrome. J Hand Ther 1998;11:171-9.

8. Yağız A. İdiyopatik karpal tünel sendromunda kesikli kısa dalga tedavisi. Ege Tıp Dergisi 1996;35:35-9.
9. Ketenci A. Yüksek frekans tedavisi. In: Tuna N, editor. Elektroterapi. 2nd ed. İstanbul, Nobel Tıp Kitabevleri Ltd; 2001. p. 93-118.

10. Füzün C (çeviren): Clayton'un Eletroterapi Kitabı. Dokuların Isıtılma yöntemleri, Isının Fizyolojik Etkileri. Izmir Güven Kitabevi, 1990:139-210.

11. Hayne CR: pulsed high frequency- Its place in physiotherapy. Physiotherapy 1984;70:459-66.

12. Raji AM. An experimental study of the effects of pulsed electromagnetic field (Diapulse) on nerve repair. J Hand Surg Br 1984;9:105-12.

13. Wilson DH, Jagadeesh P, Newman PP, Harriman DG. The effects of pulsed electromagnetic energy on peripheral nerve regeneration. Ann N Y Acad Sci 1974;238:575-85.

14. Jenrich W. Pulsed Short-Wave Therapy: mechanism and applications. Electromedica 1985;53:165-8.

15. Goats GC. Pulsed Electromagnetic(Short-wave) Energy Therapy. Br J Sports Med 1989;23:213-6.

16. Santiesteban AJ, Grant C. Post-surgical effect of pulsed shortwave therapy. J Am Podiatr Med Assoc 1985;75:306-9.

17. Wagstaff P, Wagstaff S. A pilot study to compare the efficacy of continuous and pulsed magnetic energy (Short Wave Diathermy) on the relief of low back pain. Physiotherapy 1986;72:563-6.

18. Pasila M, Visuri T, Sundholm A. Pulsating shortwave diathermy: value in treatment of recent ankle and foot sprains. Arch Phys Med Rehabil 1978;59:383-6.

19. Barclay V, Collier RJ, Jones A. Treatment of various hand injuries by pulsed electromagnetic energy (Diapulse). Physiotherapy 1983;69:186-8.

20. Stevens JC. AAEM minimonograph: the electrodiagnosis of carpal tunnel syndrome. American Association of Electrodiagnostic Medicine. Muscle Nerve 1997;20:1477-86.

21. Totten PA, Hunter JM. Therapeutic techniques to enhance nerve gliding in thorasic outlet syndrome and carpal tunnel syndrome. Hand Clin 1991;7:505-20.

22. Levine DW, Simmons BP, Koris MJ, Daltroy LH, Hohl GG, Fossel AH et al. A self-administered questionnaire for the assessment of severity of symptoms and functional status in carpal tunnel syndrome. J Bone Joint Surg Am 1993;75:1585-92.

23. Sezgin M, Incel NA, Serhan S, Camdeviren H, As I, Erdoğan C. Assessment of symptom severity and functional status in patients with carpal tunnel syndrome: Reliability and functionality of the Turkish version of the Boston Questionnaire. Disabil Rehabil 2006;28:1281-5.

24. Lundborg G. Chronic nerve compression. In: Lundborg G, ed. Nerve Injury and Repair: Regeneration, Reconstruction and Cortical Remodeling. 2nd ed. Philadelphia: Churchill Livingston; 2004:72-113.

25. Zubieta JK, Stohler CS. Neurobiological mechanisms of placebo responses. Ann N Y Acad Sci 2009;1156:198-210.

26. Ekim A, Çolak E. Karpal Tünel Sendromunda Ultrason Tedavisi: Plasebo Kontrollü Bir Çalışma. Türk Fiz Tıp Derg 2008;54:96-10.

27. Bakhtiary AH, Rashidy-Pour A. Ultrasound and laser therapy in the treatment of carpal tunnel syndrome. Aust J Physiother 2004;50:147-51.

28. Oztas O, Turan B, Bora I, Karakaya MK. Ultrasound therapy effect in carpal tunnel syndrome. Arch Phys Med Rehabil 1998;79:1540-4.

29. Ebenbichler GR, Resch KL, Nicolakis P, Wiesinger GF, Uhl F, Ghanem AH, et al. Ultrasound treatment for treating the carpal tunnel syndrome: randomised "sham" controlled trial. BMJ 1998;316:731-5.

30. Halle JS, Scoville CR, Greathouse DG. Ultrasound's effect on the conduction latency of the superficial radial nerve in man. Phys Ther 1981;61:345-50.

31. Chan L, Turner JA, Comstock BA, Levenson LM, Hollingworth W, Heagerty PJ, et al. The relationship between electrodiagnostic findings and patient symptoms and function in carpal tunnel syndrome. Arch Phys Med Rehabil 2007;88:19-24. 